\title{
Vivências de prazer e sofrimento no trabalho: um estudo com bancários
}

\author{
Experiences of pleasure and suffering at work: a study on bank employees \\ Vivencias de placer y sufrimiento en el trabajo: un estudio con empleados bancarios
}

Recebido: 04/02/2021 | Revisado: 07/02/2021 | Aceito: 09/02/2021 | Publicado: 17/02/2021

\author{
ORCID: https://orcid.org/0000-0002-3730-1021 \\ Pontifícia Universidade Católica de Minas Gerais, Brasil \\ E-mail: felipegouveap@hotmail.com \\ Fernanda de Pádua Cardoso Alves Pereira \\ ORCID: https://orcid.org/0000-0001-8887-6530 \\ Universidade Federal de Ouro Preto, Brasil \\ fernandadepadua@gmail.com \\ Silvana Alves de Oliveira \\ ORCID: https://orcid.org/0000-0002-0862-186X \\ Centro Universitário de Belo Horizonte, Brasil \\ silvanaaoliveira@gmail.com \\ Simone Aparecida Simões Rocha \\ ORCID: https://orcid.org/0000-0003-1294-2006 \\ Universidade Federal de Ouro Preto, Brasil \\ simone.a.s.rocha.ufop@gmail.com
}

Felipe Gouvêa Pena

\begin{abstract}
Resumo
Este artigo teve como objetivo analisar como um grupo de bancários, alocados em uma agência da cidade de Mariana - MG, significa as vivências de prazer e sofrimento no trabalho, a partir da aplicação do Teste de Evocação de Palavras (TEP). Em uma perspectiva qualitativa, os sujeitos de pesquisa foram convidados a evocar um conjunto de palavras diante de duas expressões indutoras. Ademais, foi solicitado que os participantes problematizassem e explicassem os termos citados. Mesmo diante de uma visão utilitarista do que seja o prazer no trabalho, os resultados enfatizam a presença de dinâmicas de sofrimento na atividade laboral. Corroborando estudos contemporâneos, o trabalho no setor bancário tem evidenciado contradições no que se refere à satisfação dos profissionais. Nesses termos, o texto contribui para o campo de estudos e apresenta uma agenda de pesquisa para novas e necessárias investigações sobre prazer e sofrimento no trabalho, ampliando os níveis de problematização.
\end{abstract}

Palavras-chave: Trabalho; Prazer; Sofrimento; Vivências; Bancários.

\begin{abstract}
This article analyses how a group of bank employees working at an agency in Mariana - MG grants meaning to pleasure and suffering at work using the Word Evocation Test (TEP). Research participants were invited to evoke a set of words through two inducing expressions following a qualitative perspective. Furthermore, participants were asked to discuss and explain the terms already listed. Even following the utilitarian view concerning the meaning of pleasure at work, the results reinforce the presence of dynamics of suffering in the workplace. Working in the banking sector has revealed some contradictions related to professional satisfaction, supporting recent studies. Accordingly, this article contributes to the field and presents a research agenda to further investigations deemed necessary on pleasure and suffering at work, thus broadening the discussion.
\end{abstract}

Keywords: Work; Pleasure; Suffering; Experiences; Bank employees.

\section{Resumen}

Este artículo busca analizar cómo un grupo de empleados bancarios, asignados en una oficina en la ciudad de Mariana - MG, da sentido a las vivencias de placer y sufrimiento en su trabajo, a partir de la aplicación de la Prueba de Evocación de Palabras. Desde una perspectiva cualitativa, los sujetos de investigación han sido invitados a evocar un conjunto de palabras ante dos términos inductores. Asimismo, se les solicitó a los participantes problematizar y explicar las expresiones mencionadas. Pese a un enfoque utilitarista acerca del placer en el trabajo, los resultados hacen énfasis a la presencia de dinámicas de sufrimiento en la actividad laboral. En consonancia con los estudios contemporáneos, el trabajo del sector bancario revela claramente contradicciones respecto a la satisfacción de los profesionales. Teniendo en cuenta lo que antecede, este texto contribuye al campo de estudios y presenta una agenda de investigación al respecto del placer y sufrimiento en el trabajo, expandiendo los niveles de problematización.

Palabras clave: Trabajo; Placer; Sufrimiento; Vivencias; Empleados bancarios. 


\section{Introdução}

O trabalho é visto como algo central na vida dos indivíduos, pois tende a alicerçar a forma com que estes interagem em comunidade e observam o mundo. A relação que o sujeito estabelece com seu trabalho em cada época é fruto de um conjunto de significados e vivências cotidianas de prazer e sofrimento. As pessoas tendem a simbolizar a sua atividade profissional de uma forma própria, considerando o impacto que o ambiente laboral produz nas outras esferas da vida (Concolatto, Rodrigues \& Oltramari, 2017).

Com o capitalismo como norte, percebe-se que a sociedade ocidental não trabalha apenas para "(sobre)viver"; os indivíduos vivem para trabalhar. A educação formal é estruturada para enfatizar essa dinâmica, a condição de emprego torna-se uma oportunidade de afirmação da identidade, e o medo do desemprego materializa-se como um grande fantasma contemporâneo. Nesses termos, a integridade (e qualidade) dos processos formativos e as condições de trabalho podem se tornar secundárias. O que está em jogo é a capacidade que os sujeitos terão para se incluir econômica e socialmente (Duarte \& Mendes, 2015).

Isso posto, uma questão se apresenta: que tipo de profissional a sociedade tem fabricado por meio da organização do trabalho? O trabalho não é a única dimensão da existência humana que gera impactos no modo como o sujeito interage com o mundo, todavia, como um palco central para as questões do capital, é importante que se problematize o modo como esses “indivíduos/produtos" estão sendo entregues ao mercado. O que se têm observado é uma tentativa explícita de moldar as pessoas conforme as "exigências", e tal processo tem desestruturado uma grande parcela da população, que se vê acometida pelo sofrimento e adoecimento causados pelos processos de exploração (Dejours, 2015).

Em meio a tantos grupos profissionais que são impactados por esse cenário, destacam-se os bancários, recorrentemente associados a casos de adoecimento no trabalho, mas também referenciados pelo senso comum como uma categoria promissora, quando se fala em remuneração. Dessa forma, diante desse contexto ambíguo, este estudo teve como objetivo analisar como um grupo de bancários significa as vivências de prazer e sofrimento no trabalho, a partir da aplicação do Teste de Evocação de Palavras (TEP). Pelo critério de acessibilidade, optou-se por realizar a investigação com os funcionários de uma agência do Banco Alfa, localizada na cidade de Mariana - MG. Além dessa breve contextualização, apresentam-se nos próximos tópicos: referencial teórico, metodologia, análise dos dados e considerações finais.

\section{Referencial Teórico}

A moldura que delineia o trabalho está ligada a diversos indicadores, como a globalização dos mercados, a competitividade exacerbada e as restruturações sociais, políticas, tecnológicas e culturais que, direta ou indiretamente, afetam as relações laborais no mundo (Tolfo \& Piccinini, 2007). A partir dessas e tantas outras variáveis, é possível notar que os princípios tomados como culturalmente "adequados" podem oportunizar ou mitigar a saúde dos trabalhadores. Quando a questão está associada à exposição dos sujeitos a condições e relações degradantes, os distúrbios e os quadros de sofrimento podem se manifestar de diferentes formas e intensidades, como também podem ser apurados de diferentes maneiras pelos teóricos organizacionais (Seligmann-Silva, 2011).

No período seguinte à Segunda Guerra Mundial, um coletivo de psiquiatras franceses começou a investigar a contribuição do trabalho para o desenvolvimento de doenças mentais. Estas primeiras pesquisas foram associadas ao campo da psicopatologia. Com a perspectiva de ampliar o campo de análise e integrar novas disciplinas, em 1992 foi proposto por Christophe Dejours - psiquiatra e psicanalista — o termo "psicodinâmica do trabalho". A recomendação era observar os conflitos psíquicos acarretados pelas vivências dos homens em seus espaços laborais, considerando o progresso dos conflitos de caráter inter e intrassubjetivos. A confrontação entre o indivíduo e a sua prática de trabalho permitiria uma melhor compreensão da dinâmica dos processos psíquicos (Carvalho, Faria, Costa \& Vergara, 2014). 
Na psicodinâmica, o trabalho sempre é visto com uma dupla atribuição; ele pode ser "estruturante" como também pode enfermar, pode fomentar o senso de dignidade ou ser alienante. Como teoria, amparada pela crítica e interdisciplinaridade, é constituída a partir da análise dos contextos de trabalho (Duarte \& Mendes, 2015), além de observar as dinâmicas pelas quais são produzidos os sistemas grupais de defesa e o compromisso ético contra os quadros de adoecimento (Seligmann-Silva, 2011).

Os trabalhos de Christophe Dejours seguiram analisando os resultados dos conflitos produzidos pelos constrangimentos organizacionais, considerando a forma de organização do trabalho e o "funcionamento psíquico" dos sujeitos. Todavia, alguns indicadores começaram a pontuar que determinados indivíduos não apresentavam sinais explícitos de adoecimento e sofrimento, mesmo em ambientes precários. Após reflexões e apurações, começou-se a observar que alguns trabalhadores constituíam estratégias de enfrentamento para as questões cotidianas. A "normalidade", como passou a ser chamada, caracterizava, então, a luta entre o sofrimento e as práticas defensivas na busca por um "equilíbrio". Logo, estabeleceu-se que também fosse possível pensar em resistência (Duarte \& Mendes, 2015).

Como deveria ser essa resistência? Individual ou coletiva? O indivíduo é, por natureza, um ser social, por isso deveria pensar e lutar coletivamente, buscando construções colaborativas. Todavia, há de se admitir que no capitalismo as relações não costumam estar alinhadas ao grupo, mas sim ao indivíduo (Freitas, 2000).

Compreender como um grupo se percebe, o que lhe faz definir um problema e como lida com tais situações são questões fundamentais para qualquer análise organizacional. O "simbolismo" de uma sociedade, a partir de um conjunto de significações, fornece parâmetros para a vivência nos ambientes público e privado. Destarte, nos moldes do sistema do capital, criou-se uma cultura do "eu e os outros" (Freitas, 2000), uma comunidade "hipercompetitiva", em que ninguém realmente se preocupa com os demais. Esse entendimento de mundo tende a promover "ressonâncias negativas" para a saúde dos sujeitos e para sua capacidade de viver em comunidade (Franco, Druck \& Seligmann-Silva, 2010).

Nesse contexto, para a Psicodinâmica do Trabalho, "o sofrimento surge quando acontece supressão do espaço existente entre organização de trabalho e trabalhador, bloqueando essa relação e provocando o domínio e a luta contra o sofrimento". Esse pode ser o resultado de sentimentos emanados de aspectos específicos que impactam a organização e se espelham através do engajamento dos corpos, das relações com os companheiros de labor e pelo assenhoreamento dos saberes dos trabalhadores. Por conseguinte, o sofrimento se materializa diante de aspectos como fadiga, rigidez hierárquica, padronização e controle excessivo, subutilização do potencial dos funcionários e irrisórias possibilidades de crescimento profissional. Em síntese, o indivíduo se encontra impossibilitado de se manifestar e, em face de tamanha pressão, acaba ficando suscetível a quadros de adoecimento (Sartori \& Souza, 2018, p. 110).

Em contrapartida, as vivências de prazer são evidenciadas quando o trabalhador se sente realizado, encontra uma identidade e vê sentido naquilo que realiza. De posse desses sentimentos, a tendência é que ele esteja disposto a contribuir para o seu grupo social. O prazer se torna explícito quando o sujeito possui liberdade para, mesmo diante das normas institucionais, negociar com a organização suas necessidades e desejos. Logo, é vital compreender que o trabalho simboliza mais do que a cessão de força para sobreviver, mas também a "remuneração social e singularidade do sujeito" em sua vinculação com o outro. A "complexidade dessa relação e a polivalência das situações reais de trabalho fazem com que sofrimento e prazer estejam em linhas limítrofes, em espaços de luta, sendo a busca por prazer e o afaste do sofrimento permanentes" (Sartori \& Souza, 2018, p. 111).

\section{Metodologia}

O estudo apresenta um escopo qualitativo. Investigações desse tipo operam a partir de diferentes concepções filosóficas, diversificando as estratégias de coleta e análise. Com um caráter interpretativo, essas pesquisas exigem um olhar atento para o fenômeno e para a ação dos sujeitos envolvidos. O foco está na subjetividade e na compreensão das vivências do grupo em 
questão (Creswell, 2010). Dessa forma, a abordagem qualitativa se apresenta como uma opção aos estudos que voltam seus olhares para as dinâmicas de prazer e sofrimento no trabalho.

A pesquisa foi desenvolvida em uma agência bancária localizada na cidade de Mariana - MG. No momento da pesquisa de campo, a unidade contava com 12 funcionários (regime CLT) e atendia uma considerável parcela da população local. Todos os integrantes da agência foram convidados e aceitaram participar do estudo. Foi garantido o anonimato a todos os sujeitos via assinatura do Termo de Consentimento Livre e Esclarecido. O Quadro 1 apresenta o perfil detalhado dos participantes. Destacase que os nomes apresentados são fictícios.

Quadro 1 - Perfil dos sujeitos.

\begin{tabular}{|c|c|c|c|c|}
\hline Nome & $\begin{array}{l}\text { Idade } \\
\text { (anos) }\end{array}$ & Escolaridade & Cargo & $\begin{array}{l}\text { Tempo de } \\
\text { Empresa }\end{array}$ \\
\hline Túlio & 23 & Ensino Superior Completo & Caixa & 04 anos \\
\hline Vagner & 31 & Ensino Superior Completo & Auxiliar Administrativo & 08 anos \\
\hline Gleisson & 34 & Ensino Superior Completo & Gerente de Pessoa Jurídica & 10 anos \\
\hline Laura & 23 & Ensino Superior Completo & Gerente de Pessoa Jurídica & 03 anos \\
\hline Elias & 48 & Ensino Superior Completo & Gerente de Pessoa Física & 28 anos \\
\hline Carolina & 55 & Ensino Médio Completo & Caixa & 36 anos \\
\hline Suelen & 31 & Ensino Superior Completo & Caixa & 07 anos \\
\hline Patrícia & 31 & Ensino Superior Completo & Gerente de Pessoa Física & 06 anos \\
\hline Edna & 29 & Ensino Superior Completo & Supervisora & 06 anos \\
\hline Lindomar & 35 & Ensino Superior Completo & Gerente Administrativo & 10 anos \\
\hline Marcos & 29 & Ensino Superior Completo & Gerente de Pessoa Jurídica & 11 anos \\
\hline Nivaldo & 35 & Ensino Superior Completo & Gerente de Pessoa Física & 07 anos \\
\hline
\end{tabular}

Fonte: Dados da pesquisa.

Optou-se por realizar a coleta dos dados via Teste de Evocação de Palavras (TEP). Referenciado na teoria das representações sociais, o TEP é "um método de coleta de dados por meio do qual o pesquisador solicita aos sujeitos de pesquisa que mencionem, oralmente ou por escrito, um determinado número de palavras relacionadas a uma expressão indutora" (Vergara, 2005, p. 243). A ideia é que, ao propor uma "questão-estímulo", os participantes possam elencar um conjunto de palavras. Elas tendem a simbolizar como as pessoas observam, significam e vivenciam a questão. Neste estudo, o recurso foi utilizado da seguinte forma: foi apresentada a expressão indutora "prazer no trabalho" e solicitada a evocação de quatro palavras. Em seguida, foi requisitado que os participantes problematizassem e explicassem os termos citados. O processo foi gravado com a autorização dos sujeitos. O mesmo procedimento foi repetido com a sentença "sofrimento no trabalho". Ressalta-se que a ordem das palavras evocadas simboliza o grau de representação do termo para os sujeitos.

Por fim, a apuração dos dados coletados foi feita conforme os pressupostos da análise de conteúdo. O uso dessa técnica a partir da leitura e da interpretação dos contornos das falas dos sujeitos possibilita descrições objetivas, sistemáticas e 
categorizadas (Bardin, 2004), favorecendo a compreensão das vivências de prazer e sofrimento no trabalho.

\section{Análise dos Dados}

A seguir, apresentam-se os resultados do Teste de Evocação de Palavras.

Quadro 2 - Teste de Evocação de Palavras - TEP.

\begin{tabular}{|c|c|c|c|}
\hline \multicolumn{5}{|c|}{ PRAZER NO TRABALHO } \\
\hline Túlio & Vagner & Gleisson & Laura \\
\hline 1. Conquistas & 1. Satisfação & 1. Salário & 1. Respeito \\
\hline 2. Reconhecimento & 2. Benefícios & 2. Ambiente & 2. União \\
\hline 3. Equipe & 3. Relacionamento & 3. Satisfação & 3. Confiança \\
\hline 4. Salário & 4. Salário & 4. Qualidade & 4. Realização \\
\hline Elias & Carolina & Suelen & Patrícia \\
\hline 1. Equipe & 1. Amor & 1. Realização & 1. Conhecimento \\
\hline 2. Segurança & 2. Alegria & 2. Satisfação & 2. Satisfação \\
\hline 3. Carreira & 3. Satisfação & 3. Crescimento & 3. Entrega \\
\hline 4. Salário & 4. Pessoas & 4. Salário & 4. Salário \\
\hline Edna & Lindomar & Marcos & Nivaldo \\
\hline 1. Flexibilidade & 1. Amizade & 1. Ambiente & 1. Reconhecimento \\
\hline 2. Autonomia & 2. Atendimento & 2. Dinheiro & 2. Remuneração \\
\hline 3. Tranquilidade & 3. Resolução & 3. Reconhecimento & 3. Equipe \\
\hline 4. Conhecimento & 4. Salário & 4. Disponibilidade & 4. Flexibilidade \\
\hline
\end{tabular}

Fonte: Dados da pesquisa.

Inicialmente, chama atenção o fato de nove dos doze participantes evocarem palavras como "salário", "dinheiro", "remuneração" e "benefícios" no TEP de prazer no trabalho. Por mais que apenas Gleisson tenha dito "salário" como primeiro item, é notável como existe um entendimento coletivo de que o aspecto financeiro possui considerável valor na atividade laboral. Os participantes confirmaram que a remuneração praticada pelo setor bancário está acima da média de muitas categorias, sendo um fator de grande estímulo para os profissionais.

Ao mesmo tempo, destacou-se a categoria formada pelas palavras: "equipe", "pessoas", "confiança", "relacionamento", "ambiente", "união" e "amizade", não somente pelas palavras evocadas, mas também pelas justificativas apresentadas pelos participantes. Mesmo diante de algumas variáveis negativas, como será exposto a seguir, a maioria percebe o trabalho como uma oportunidade para estabelecer vínculos fraternos, que por muitas vezes amenizam algumas situações cotidianas e contribuem para a permanência dos membros na organização.

Em consonância, dez dos indivíduos ressaltaram as palavras "satisfação", "reconhecimento", "realização" e "carreira" no TEP de prazer no trabalho. Segundo eles, a empresa tem possibilitado algumas oportunidades para aqueles que comunguem dos valores institucionais e "vistam a camisa". Há uma relação de troca estabelecida na fala dos sujeitos, mas fica silenciado qual seria a força dos funcionários em um eventual processo de negociação com as instâncias da organização que estão fora da agência. 
Quadro 3 - Teste de Evocação de Palavras - TEP.

\begin{tabular}{|c|c|c|c|}
\hline \multicolumn{5}{|c|}{ SOFRIMENTO NO TRABALHO } \\
\hline Túlio & Vagner & Gleisson & Laura \\
\hline 1. Cobrança & 1. Desvalorização & 1. Pressão & 1. Desrespeito \\
\hline 2. Metas & 2. Cansaço & 2. Sobrecarga & 2. Sobrecarga \\
\hline 3. Estresse & 3. Metas & 3. Estresse & 3. Acúmulo \\
\hline 4. Responsabilidade & 4. Estresse & 4. Reconhecimento & 4. Insatisfação \\
\hline Elias & Carolina & Suelen & Patrícia \\
\hline 1. Equipe & 1. Metas & 1. Perseguição & 1. Cobrança \\
\hline 2. Insegurança & 2. Assédio & 2. Reconhecimento & 2. Metas \\
\hline 3. Ansiedade & 3. Diferenças & 3. Apatia & 3. Estresse \\
\hline 4. Pressão & 4. Omissões & 4. Preferências & 4. Preferências \\
\hline Edna & Lindomar & Marcos & Nivaldo \\
\hline 1. Pressão & 1. Sobrecarga & 1. Metas & 1. Metas \\
\hline 2. Estresse & 2. Desamparo & 2. Assédio & 2. Pressão \\
\hline 3. Tensão & 3. Empenho & 3. Estresse & 3. Estresse \\
\hline 4. Sobrecarga & 4. Diferenças & 4. Cobrança & 4. Preocupação \\
\hline
\end{tabular}

Fonte: Dados da pesquisa.

O TEP de sofrimento no trabalho também apresenta informações interessantes para análise. As palavras "metas" e "pressão" foram evocadas por nove dos participantes, estando em posição de destaque para muitos. Em uma perspectiva de controle e produtividade, fica evidente que os funcionários dessa agência vivem uma história que se repete no mundo corporativo. Contudo, segundo os entrevistados, o ambiente de tensão e as metas inalcançáveis ganham contornos próprios nas instituições bancárias, principalmente no banco do qual a agência faz parte.

O processo de denúncia continua com a macrocategoria composta pelas palavras: "assédio", "perseguição", "estresse", "desamparo", "ansiedade", "insatisfação" e "cansaço". Ela ilustra uma dinâmica de sofrimento no trabalho em diferentes instâncias. Ao problematizarem os termos evocados, os participantes relataram que os quadros de ansiedade e estresse são cada vez mais recorrentes na organização. A cobrança exacerbada e o constante sentimento de incompletude que o banco aplica aos funcionários fazem com que aumentem os níveis de insatisfação. Carolina menciona que aos poucos o assédio está ficando institucionalizado, como se não houvesse nada errado e estivesse amparado pela cultura da produtividade.

As palavras "desvalorização", "desrespeito", "insegurança", "apatia" e "preocupação" também foram pontos de relevo no TEP de sofrimento no trabalho. Os participantes se mostraram receosos com a eminente possibilidade de desemprego, pelo momento que a instituição passa e pelo movimento de reestruturação que estava em curso no período da abordagem. Disseram que não possuem um canal de escuta transparente, gerando sentimentos de insegurança e desvalorização. Como dito pelo grupo, a organização se coloca à disposição do funcionário apenas quando possui um interesse específico.

Torna-se oportuno frisar algumas contradições nas falas dos sujeitos, com destaque para as participações de Vagner, Laura, Elias e Edna. O primeiro evocou as palavras "satisfação" e "desvalorização" nos TEPs de prazer e sofrimento no trabalho, respectivamente. Ao ser questionado, demonstrou certo incômodo com a primeira palavra, como se mudasse de ideia. Laura fez algo semelhante, ao elencar "respeito" e depois "desrespeito". No entanto, deixou claro que se trata de uma questão contingencial, como se os significados pudessem mudar diante de uma atitude dos superiores ou dos seus pares. Isso foi pontuado por Elias ao 
justificar as razões que o fizeram evocar a palavra "equipes" nos dois testes. Por fim, mas não menos contraditória, tem-se a fala de Edna, que disse "tranquilidade" no primeiro TEP e "tensão" no segundo. Percebe-se uma incoerência da participante, mesmo com a justificativa de que as palavras estariam representando um momento pontual da sua vida laboral.

\section{Considerações Finais}

Entende-se que o objetivo do artigo foi alcançado e que o instrumento de coleta foi adequado para a investigação. Os resultados demonstram que os sujeitos visualizam o "prazer no trabalho", principalmente, a partir da remuneração e dos laços de amizade. Observando outros estudos, a remuneração sempre é algo recorrente, mas a questão fraterna evidenciada nesta pesquisa traz uma contribuição específica para a análise. Já o "sofrimento no trabalho" esteve materializado em diversas falas dos participantes, com realce para os indicativos de assédio e estresse, além do regular discurso de controle e dominação.

O estudo traz algumas contribuições, mas também possui limitações. Como ponto de reflexão, é importante pontuar que a aplicação foi realizada nos intervalos de descanso dos funcionários dentro do banco. Isso pode, de alguma forma, ter influenciado algumas respostas e inibido outras, mesmo diante da assinatura do Termo de Consentimento que garantia o anonimato. Ademais, a falta de literatura internacional pode ter enviesado o artigo, mesmo que ele tenha tido como premissa a observação de uma unidade de análise local. Mesmo diante desses pontos de possível aprimoramento, acredita-se que o artigo contribui para o campo de estudos ao alinhar os debates de prazer e sofrimento no trabalho ao uso do Teste de Evocação de Palavras. O texto oportuniza novas frentes de análise.

Como agenda de pesquisa, sugerem-se os seguintes estudos: a) ampliar a aplicação do teste para outras unidades, com o intuito de traçar um panorama da instituição; b) realizar um grupo focal para refinamento das questões levantadas; c) realizar as duas propostas anteriores em bancos distintos e depois traçar uma análise comparativa; d) realizar uma associação específica entre as falas dos líderes e as dos liderados.

\section{Referências}

Bardin, L. (2004). Análise de conteúdo. Edições 70.

Carvalho, J. L. F., Faria, M. D., Costa, A. S. M., \& Vergara, S. C. (2014). Psicodinâmica do trabalho e sofrimento na literatura do "poeta proletário". FarolRevista de Estudos Organizacionais e Sociedade, 1(2), 383-439.

Concolatto, C. P., Rodrigues, T. G., \& Oltramari, A. P. (2017). Mudanças nas relações de trabalho e o papel simbólico do trabalho na atualidade. Farol Revista de Estudos Organizacionais e Sociedade, 4(9), 341-390.

Creswell, J. W. (2010). Projeto de Pesquisa: métodos qualitativo, quantitativo e misto. Artmed.

Dejours, C. (2015). A loucura do trabalho: estudo de psicopatologia do trabalho. Cortez.

Duarte, F. S., \& Mendes, A. M. (2015). Da escravidão à servidão voluntária: perspectivas para a clínica psicodinâmica do trabalho no Brasil. Farol - Revista de Estudos Organizacionais e Sociedade, 2(3), 71-134.

Franco, T., Druck, G., \& Seligmann-Silva, E. (2010). As novas relações de trabalho, o desgaste mental do trabalhador e os transtornos mentais no trabalho precarizado. Revista Brasileira de Saúde Ocupacional, 35(122), 229-248.

Freitas, M. E. (2000). A questão do imaginário e a fronteira entre a cultura organizacional e a psicanálise. In: Motta, F. C. P., \& Freitas, M. E. (Orgs.). Vida psíquica e organização (41-73). Rio de Janeiro: Editora FGV.

Sartori, S. D., \& Souza, E. M. (2018). Entre sofrimento e prazer: vivência no trabalho e intervenção em crises suicidas. REAd - Revista Eletrônica de Administração, 24(2), 106-134.

Seligmann-Silva, E. (2011). Trabalho e desgaste mental: o direito de ser dono de si mesmo. Cortez.

Tolfo, S. R., \& Piccinini, V. (2007). Sentidos e significados do trabalho: explorando conceitos, variáveis e estudos empíricos brasileiros. Psicologia e Sociedade, 19(ed.esp.), 38-46.

Vergara, S. C. (2005). Métodos de Pesquisa em Administração. Atlas. 